\title{
Effect of Discharge Plan on Quality of Life among Elderly Women Undergoing Uterine Prolapse Surgery
}

\author{
AMAL I. FOUAD ${ }^{1}$, EBTESAM MO'AWAD EL-SAYED EBIED ${ }^{2}$ \\ ${ }^{1}$ Department of community and gerontological nursing, Faculty of Nursing Fayoum University \\ ${ }^{2}$ Department of Gerontological Nursing, Faculty of Nursing, Cairo University, \\ Correspondence to Ebtasam Mo"awad El Sayed Ebied, Email: ebtesam.ebied@yahoo.com
}

\begin{abstract}
Background: Uterine prolapse is a highly prevalent disorder affecting as many as $50 \%$ of women above 60 years. Aim: To evaluate the effect of discharge plan on quality of life among elderly women undergoing uterine prolapse surgery.

Methodology: one group pre-posttest quasi experimental design. Setting: gynecological outpatients' clinics. Sampling: A purposive sample of 105 elderly women undergoing uterine prolapse surgery. Tools: 1 . structured questionnaire of personal and medical data. 2. A questionnaire to assess knowledge about uterine prolapse surgery. 3. Who Quality Of Life-bref to assess bio-psychosocial and environmental quality of life domains.

Results: Showed statistically significant differences between pre \& post- test regarding knowledge as well as quality of life domains scores. Conclusion: implementation of the discharge plan resulted in improvement in many quality of life domains.
\end{abstract}

Conclusion: implementing discharge plans for elderly women undergoing uterine prolapse surgery.

Keywords: Quality of life, elderly women, prolapsed uterus

\section{INTRODUCTION}

Uterine prolapse is defined as falling of the uterus, when the muscles of the pelvic are strained to a point where women can no longer support the positioning of the uterus. The uterus drops from its normal position in the pelvis cavity, descending into and eventually, in the extreme stages, out of the vagina. It is a progressive condition that typically occurs in post-menopausal women (CAED, 2018).

Uterine prolapse is one of the most common causes of reproductive health morbidity which influence women's quality of life particularly older women in developing countries (Aki, et al., and Thapa, et al., 2014). Many elderly women don't seek medical help due to sense of shame caused by the condition which affects a sensitive part of the women's body. This consequently could result in absence of database about the actual number of women affected by uterine prolapse (Tamarkar, 2015).

According to World Health Organization estimates, reproductive ill-health accounts for $33 \%$ of the total disease burden for women globally. According to women's health initiative, $14.2 \%$ of the 16,616 women were diagnosed with uterine prolapse. Another study suggests that uterine prolapse is present among $20 \%$ of post-menopausal women. Estimates by United Nations Population Fund suggest that about 600,000 women require immediate health care for uterine prolapse (World Health Organization, 2018).

Uterine prolapse is one of the most widespread reproductive health and social problem affecting women's health globally (Detollenaera, et al., 2015). Demographic Health Survey (2016) data showed that up to $7 \%$ of women of reproductive age group (49 - 69 years) suffered from uterine prolapse. Additionally, for uterine prolapse there is no age group difference for this problem and women as old as eighty may be the sufferers. The report also showed that $6 \%$ of women who had ever given birth experienced symptoms of uterine prolapse (Institute of Medicine and The United Nations Fund for Population Activities, 2018).

Uterine prolapse is usually classified into four anatomical stages corresponding to the severity of the condition. For the first stage, the uterus leaves its place but is still inside the vagina. In the second stage, the uterus leaves its place and comes up to the opening of the vagina. For two lower stages (I and II), conservative managements including pelvic floor muscles training or ring pessary insertion are considered the best options (The United Nations Fund for Population Activities, \& Sanchariko, 2017).

Risk factors of uterine prolapse include age and parity, extensive physical work during pregnancy and immediately after delivery, as well as the use of unskilled birth attendants, moreover, predisposing factors includes obstetric conditions resulting from excessive stretching and tearing, multiple deliveries, vaginal delivery, and high body mass index (Gyhagen, et al., 2015).

Common symptoms include pelvic pressure, discomfort, visible bulging, and sexual impairment. Clinically, symptoms of uterine prolapse are organized into four groups according to presentation: vaginal, urinary, bowel, and sexual (Baessler, et al., 2018). Quality of life are graded according to elderly women's perceived symptoms and experiences in daily life and determine severity according to the degree, or stage, of prolapsed uterus (Fritel, et al., 2015). Stage I is usually identified during clinical examination. In stage II, women may experience symptoms but frequently do not seek medical help. Symptoms become more severe as the uterus drops further into the vaginal canal (Stage III). In stage IV, the uterus protrudes from the vagina, requiring emergency care (Streicher, 2015).

Management of uterine prolapse vary according to degree, first and second degree of uterine prolapse can be treated with ring pessaries, which inserted into the vagina and so stretches the vaginal walls, often in combination 
with pelvic floor exercises. Third degree uterine prolapse requires surgical interference (Lamichhane \& Tiwari, 2015).

Complications of uterine prolapse surgery include recurrence, bladder or bowel injury, urinary incontinence, infections, wound complications, persistent abdominal or pelvic pain, painful sexual intercourse (National Institute for Health, 2017). Gerontological nurses have a key role in educating elderly women about postoperative complication prevention. It is essential that women should have adequate knowledge about uterine prolapse surgery (Summan, 2017). Uterine prolapse can be prevented by raising women awareness regarding preventive measures such as, maintaining healthy life style, taking adequate rest during postnatal period, performing Kegel exercise, maintaining ideal body weight, avoiding constipation, encouraging antenatal care and smoking cessation (Ministry Of Health and Population, 2018). Therefore; this study aims to evaluate the effect of discharge plan on quality of life among elderly women undergoing uterine prolapse surgery.

Significance of the study: Uterine prolapse are common debilitating conditions among women across the world. In developed countries, one in every four women experience uterine prolapse. Evidence-based data from these countries have established that advancing age, parity, obesity and vaginal birth are the risk factors of uterine prolapse. However, uterine prolapse is under reported among women in low/middle-income countries (LMICs). (Ministry of Health Nepal, 2018). In a 2018 study from Egypt, $56 \%$ of 509 ever-married women between the ages of 60 and more had prolapsed uterus and 2,990 married women surveyed for uterine prolapse, cases were diagnosed in $7.6 \%$. (Hod, et al., 2018).

Uterine prolapse impair quality of life via physical activity limitations, depression, poor self-image, as well as impairment of participation in social activities. Srikrishna, Robinson, Cardozo, et al (2008). Surgery is the definitive treatment of uterine prolapse and is feasible and generally safe in elderly patients. As both the incidence and prevalence of prolapse surgery increase with age, pelvic organ prolapse becomes an increasingly bothersome disorder in older patient population. Shah, Ginzberg, \& Whitmore (2016).

Uterine prolapse will continue to be a major health problem in the elderly women over the next few decades, so, there is a need to maintain a high quality of life standard among that target group. There are little studies that examined the effect of discharge planning on elderly women's undergoing uterine prolapse surgery, so conducting this study will help gerontological nurses in educating elderly women about uterine prolapse surgery and postoperative complications prevention.

The objective of the study was to evaluate the effect of discharge plan on quality of life among elderly women undergoing uterine prolapse surgery.

\section{Research hypotheses:}

H1.1- Elderly women with uterine prolapse who will be exposed to the discharge plan will exhibit higher post total knowledge mean scores than in the pre-test.

H1.2- Elderly women with uterine prolapse who will be exposed to the discharge plan will exhibit higher post total quality of life mean scores than in the pre-test.

\section{SUBJECTS AND METHODS}

Research design: A quasi experimental one group pre/post- test research design was used to test the intervention (Kettner, Moroney, \& Martin, 2014).

Setting: This study was carried out in selected outpatients' clinics in two gynecological hospitals (Al Demerdash University hospital and Al- Galaa hospital). Al- Galaa hospital consists of four buildings; the first building contains the outpatient clinics and the administration offices, the second building contains incubators, natural birth stalls, the antenatal department, the postpartum department, and operation room, the third building for examinations and $\mathrm{x}$ ray. The fourth building is for inpatient of preeclampsia cases. Al Demerdash University hospital consists of one building; on the ground floor, there are outpatient clinics, $x$ rays, laboratories, the first floor is the administration offices, and the second floor has maternity stalls and preterm incubators, an antenatal department, a postpartum department, and the third floor after operation room.

Sampling: A purposive sample of 105 elderly women undergoing uterine prolapse surgery representing about $5 \%$ of the total attendees in the two outpatient clinics.

Inclusion criteria: All elderly women who suffer from prolapsed uterus requiring surgery, aged 60 years and above, with different educational levels, fully oriented, and didn't exposed to any prior learning experience about uterine prolapse and agree to participate in the study.

Exclusion criteria: elderly women with a mental disorder

(such as dementia or cerebrovascular stroke) that hinders communication.

Tools of data collection: Three tools were used for data collection:

Tool I: structured questionnaire consisted of four parts:

Part one: It included elderly women personal data such as age, educational level, and income, number of children, occupation, and duration of uterine prolapse. Part two included history of past chronic disease and medications. Part three included day time symptoms caused by uterine prolapse. Part four included body mass index (BMI) according to World Health Organization (2006).

Tool II: Elderly women's knowledge questionnaire it included questions about meaning, risk factors, symptoms, degrees, complications, treatment and management of uterine prolapse. The scoring system regarding elderly women's knowledge was as follow: correct answers were given score 2, whereas, incorrect answers were given score 1. The total knowledge score level was categorized as "good level of knowledge" if score is more than or equal to $75 \%$ and as "fair level of knowledge" if the score ranges from 50 \%to less than $75 \%$. Or "weak level of knowledge" if the score is less than $50 \%$.

Tool III: a 26-item WHOQUALITY OF LIFE-BREF, (2017) to measure elderly women's quality of life. It contains 2 questions about overall quality of life rating and subjective health satisfaction and the other 24 questions are about four quality of life domains (physical health (7 items), psychological health (6 items), social health (3 items) and environmental health (8 items)). Scoring is a Likert scale range from 1 (very dissatisfied or very poor) to 5 (very satisfied), with a higher score indicating better quality of life. Domain scores was calculated by taking the mean of 
all items in each domain and then multiply in 4 the transformed to Ob to $100 \%$ scale. The WHOQUALITY OF LIFE-BREF has been translated into the Arabic language, and the translated version showed internal reliability (Cronbach's alpha $=0.87$ ).

Validity \& reliability of study tools: Content validity was done by a panel of five experts, two in geriatrics specialty and two in gynecology specialty, and one in gerontological nursing specialty.

Field work: An official permission was obtained from the responsible authority before conducting this study explaining the purpose of the study. An extensive review of literature was done to develop data collection tools and program content. Data collection started, and it took 6 months (from November 2018 to the end of April 2019). The researchers interviewed elderly women individually in a private place in the outpatient clinics to explain the purpose of the study and obtain the informed written consent and fill in the questionnaires (Tool I, Tool II and Tool III). The average time consumed in answering the questionnaire was thirty minutes. The researchers then started implementing the discharge plan steps about prolapsed uterus after finishing the pretest. Post-test was done immediately after implementation of the discharge plan steps.

Pilot study: A pilot study was conducted on $11(10 \%)$ of elderly women with uterine prolapse to test the applicability and feasibility of the study tools. Modifications were done accordingly

Ethical consideration: An approval of research ethics committee in Fayoum university was obtained, then, researchers assured anonymity and confidentiality of elderly women's data. Elderly women were informed that they have the right to withdraw from the study at any time throughout the intervention and that data will not be used for current research purpose only.

Description of discharge plan: discharge plan (9 sessions) consisted of four phases:

1. Assessment phase; researcher interviewed elderly women and filled in the questionnaires (pre-test).

2. Planning phase; this phase included analysis of the pretest findings; researchers designed discharge plan objectives and content according to the elderly women's learning needs. The general objective of the program is to design and implement discharge plan for elderly women undergoing uterine prolapse surgery; and then to evaluate its effect on elderly women knowledge and quality of life. Discharge plan content included basic knowledge about prolapsed uterus such as meaning of prolapsed uterus, signs and symptoms of prolapsed uterus, degree of prolapsed uterus, risk factors of prolapsed uterus, management and types of uterine prolapse surgery, complications of prolapsed uterus, postoperative nursing care, and prevention of complications.

3. Implementation phase included implementation of the designed discharge plan steps at the previously mentioned setting in a special room in 2 separate main sessions for all contents at morning shift three days /weeks. Discussion method was used and audiovisual material such as boosters, slide shows, video films were also used.

4. Evaluation phase; after implementation of the discharge plan, the researchers used a post-test to evaluate improvements in quality of life and level of knowledge among elderly women undergoing uterine prolapse surgery before and after implementation of the discharge plan.

Statistical Analysis: The collected data were analyzed and presented in tables with suitable statistical test. All data were recorded, collected and analyzed by using the Statistical Package for the Social Sciences 18.0 for Microsoft (SPSS). Descriptive Statistics with numerical data was expressed as means \pm standard deviations (SD). Inferential statistics such as $\mathrm{T}$. test was used. Statistical significance was achieved if $p$ was $<0.05$.

\section{RESULTS}

Table 1 clarified that there were statistically significant relationships between all items of knowledge except meaning of prolapsed uterus before and after introduction of the discharge plan at $\mathrm{p}$-value at $\mathrm{P}<0.05$.

Table 2 clarified that there were statistically significant relationships between all items of physical quality of life domain before and after introduction of the discharge plan at $p$-value at $P<0.05$.

Table 1: Statistical differences among elderly women according to level of knowledge about uterine prolapse surgery complications before/after discharge plan. $(n=105)$

\begin{tabular}{|l|c|c|c|c|c|c|}
\hline \multirow{2}{*}{ Items } & \multicolumn{2}{|c|}{ Before } & \multicolumn{2}{|c|}{ After } & \multirow{2}{*}{ t } & \multirow{2}{*}{$\mathbf{p}$-value } \\
\cline { 2 - 6 } & Mean & SD & Mean & SD & & \\
\hline Meaning of prolapsed uterus. & 3.01 & 0.73 & 3.06 & 0.81 & 0.49 & 0.62455 \\
\hline Signs \& symptoms of prolapsed uterus. & 2.32 & 0.81 & 3.61 & 0.49 & 13.34 & $0.00000^{*}$ \\
\hline Degree of prolapsed uterus and related surgery type. & 2.93 & 0.68 & 3.44 & 0.50 & 6.80 & $0.00000^{*}$ \\
\hline Risk factors of prolapsed uterus. & 2.60 & 0.80 & 3.47 & 0.50 & 10.12 & $0.00000^{*}$ \\
\hline Complications of prolapsed uterus. & 2.68 & 0.73 & 3.29 & 0.45 & 7.56 & $0.00000^{*}$ \\
\hline Prevention of surgery complication. & 2.35 & 0.64 & 3.63 & 0.49 & 15.61 & $0.00000^{*}$ \\
\hline Total knowledge score & 15.90 & 2.49 & 20.49 & 2.10 & 16.31 & $0.00000^{*}$ \\
\hline
\end{tabular}

Table 2: Statistical differences among elderly women according to physical quality of life mean scores before and after implementation of discharge plan $(\mathrm{n}=105)$

\begin{tabular}{|l|l|l|l|l|l|}
\hline \multirow{2}{*}{$\begin{array}{l}\text { Physical quality of life } \\
\text { domain }\end{array}$} & Before & \multicolumn{3}{l|}{ After } & \\
\cline { 2 - 5 } & Mean & SD & Mean & SD & \\
\hline General health perception & 41.8 & 19.7 & 54.0 & 26.4 & $<1.000^{*}$ \\
\hline Uterine prolapse impact. & 28.9 & 25.1 & 42.9 & 28.4 & $<0.001^{*}$ \\
\hline Physical limitation. & 46.7 & 19.8 & 54.5 & 24.1 & $0.024^{*}$ \\
\hline Personal relationships. & 44.5 & 20.6 & 54.1 & 23.7 & $0.005^{*}$ \\
\hline Sleep disturbance. & 47.1 & 21.3 & 55.6 & 23.1 & $0.014^{*}$ \\
\hline Sexual problems & 43.1 & 19.7 & 52.7 & 22.6 & $0.004^{*}$ \\
\hline ADL limitations. & 45.9 & 20.2 & 58.2 & 20.9 & $<0.001^{*}$ \\
\hline
\end{tabular}

Table 3 clarified that there was no significant relationship between items of social quality of life domain except social contact leisure activities before and after introduction of the discharge plan at $p$-value at $P<0.05$. Table 4 clarified that there was no significant relation between items of psychological quality of life domain except depression \& emotional problems before and after introduction of the discharge plan at $\mathrm{p}$-value at $\mathrm{P}<0.05$. 
Table 3: Statistical differences among elderly women according to social quality of life mean scores before and after implementation of discharge plan $(\mathrm{n}=105)$

\begin{tabular}{|l|c|c|c|c|c|}
\hline \multirow{2}{*}{$\begin{array}{l}\text { Social quality of life } \\
\text { domain }\end{array}$} & \multicolumn{2}{|c|}{ Before } & \multicolumn{2}{c|}{ After } & \multirow{2}{*}{ p- value } \\
\cline { 2 - 5 } & MEAN & SD & MEAN & SD & \\
\hline Intimacy. & 61.2 & 20.5 & 65.0 & 23.4 & 0.340 \\
\hline Social support contact leisure & 59.0 & 16.6 & 66.2 & 19.3 & 0.178 \\
\hline $\begin{array}{l}\text { Social } \\
\text { activities. }\end{array}$ & & 17.5 & 61.2 & 21.2 & $0.027^{\star}$ \\
\hline Social limitations. & 64.1 & 21.2 & 65.5 & 23.1 & 0.673 \\
\hline
\end{tabular}

Table 4: Statistical differences of elderly women according to psychological quality of life mean scores before and after implementation of discharge plan $(\mathrm{n}=105)$

\begin{tabular}{|l|c|c|c|c|c|}
\hline \multirow{2}{*}{$\begin{array}{l}\text { Psychological quality of } \\
\text { life domain }\end{array}$} & \multicolumn{2}{|c|}{ Before } & \multicolumn{2}{c|}{ After } & \multirow{2}{*}{ p- value } \\
\cline { 2 - 5 } & Mean & SD & Mean & SD & \\
\hline Depression. & 23.7 & 8.7 & 8.6 & 8.6 & $<0.001^{*}$ \\
\hline Anxiety. & 10.7 & 2.2 & 11.1 & 2.6 & 0.212 \\
\hline Worry. & 13.0 & 5.0 & 13.8 & 2.7 & 0.620 \\
\hline Emotional problems. & 12.0 & 2.4 & 13.0 & 3.6 & $0.002^{*}$ \\
\hline Environmental problems. & 2.70 & 1.06 & 2.30 & 1.29 & 0.190 \\
\hline
\end{tabular}

\section{DISCUSSION}

Uterine prolapse is one of the common causes of gynecological morbidity and major public health problem (Shrestha, et al., 2014). The incidence of uterine prolapse is increasing nowadays due to lack of awareness about risk factors, signs and symptoms and preventive measures. Literature revealed that uterine prolapse has been unsatisfactorily addressed and is considered a sensitive topic among women, families and communities which lead to inappropriate management of this health condition (Chen, 2017). According to personal characteristics of elderly women in the current study, more than half elderly women's age ranged between (60-70y). Regarding educational level, more than one third of elderly women completed diploma education. These finding is supported by Binjwala et, al., (2015) who studied uterine prolapse and its impact on women's quality of life in Nepal and found that, women older than $60 y$ were more prone to uterine prolapse than women who aged less than sixty $(90 \%$ Vs $83 \%)$ respectively. Authors also found that illiterate women had more tendency to experience uterine prolapse problems than literate women (83\% \& 56\%) respectively.

Current study revealed that, majority of elderly women had insufficient income, furthermore, more than half of them had more than three children and had prolapsed uterus for more than 6 year. These findings are in agreement by Osama EL Kady et, al., 2017 who studied the prevalence of pelvic floor disorders in both vaginal and cesarean deliveries and their impact on quality of life in Egypt and found that the prevalence of prolapsed uterus is higher among elderly women with low socio-economic and who had more than three children and those who experienced uterine prolapse for a duration more than 5 years. From current researchers' point of view insufficient income could contribute to inability to access required quality health care services or inability to pay high cost of surgical intervention.

Findings of the present study also found that, the most common chronic disease as mentioned by the studied elderly women were hypertension, followed by chest disease, gastrointestinal disorders, arthritis, renal disease \& neurology disease, cancer and skin disease, diabetes mellitus, cardiac disease and liver diseases. In a 2018 study in the United States, 27,342 women were evaluated in the women's health; the relative frequency of uterine prolapse occurrence was $50 \%$ among women with urinary incontinence and was $15-20 \%$ among women over 60 (Tracee, 2018), moreover, the mean number of medications used by elderly women to treat previous chronic conditions was three medications. These findings are incongruent with Tracee Cornforth, 2019 who stated in a study titled "common conditions that can affect the uterus" in Texas that a number of medical conditions can affect a woman's uterus and cause pain, such as polyps, endometriosis, fibroids, cancer, dysmenorrheal and menorrhagia.

Current study findings also showed that, percentages of daytime symptoms caused by prolapsed uterus were heaviness feeling of vagina that affects walking activities (around half of the studied elderly women), followed by vaginal bulge and sexual discomfort problems. These findings are supported by Niema, et. al., 2016 who reported similar complaints of heaviness feeling from the vagina that affect walking activities, vaginal bulge causing significant discomfort and not being sexually active for years because of uterine prolapse.

Regarding BMI, about one quarter of the studied elderly women weight was normal, whereas, about half of them were overweight or obese. Similarly, Deborah, et al., 2014 who studied "symptoms of uterine prolapse in over weight and obese women before and after weight loss" in Nepal mentioned that population of overweight and obese women and found that over half of participants reported at least one prolapsed symptom and one-quarter reported more than one symptom. The only symptom associated with increasing BMI was bothersome vaginal bulging.

Current study clarified that there were statistically significant relationships before and after the discharge plan in relation to all items of knowledge except for the meaning of prolapsed uterus. This finding goes with Summan, (2013), who studied "Effectiveness of nursing intervention package on prevention of utero-vaginal prolapse among mothers " in Mangalore stated that Uterine prolapse still neglected for so long and there is only a little literature on this topic. Moreover, Shrestha et al., (2014) who studied "Women's experiences and health care-seeking practices in relation to uterine prolapse" in Nepal, found that majority of women in the study had never heard about uterine prolapse, and only $37.5 \%$ of them had ever heard about it. This finding was in line with Essa, (2015) who studied women's awareness and reactions toward symptoms of genital prolapse in Alexandria and reported that, most of the studied women reflected unaccepted level of knowledge regarding genital prolapse.

From current researchers' point of view, lack of women's knowledge about uterine prolapse surgery indicate an urgent need for educational programs to raise elderly women's awareness regarding uterine prolapse. Elderly women in the current study believed that uterine prolapse is a disease that affects only old and grand-multipara women. In the present study a significant relationship was found between all items of physical quality of life domain before and after the discharge plan. These findings are in agreement with a study by Osama EL Kady et, al., (2017) who studied assessment of the prevalence of pelvic floor disorders in both vaginal and cesarean deliveries and its impact on quality of life in Egypt showed that the prolapsed uterus had negatively impacted the physical quality of life 
among the affected women. Osama's study showed that more women had self- described their general health condition at the time of the preprogram as worse than those post program women of the both group with their King's Health Questionnaire (KHQ) subscale scores (Meant SD) $54.0 \pm 26.4,41.8 \pm 19.7$ respectively $(P<0.001)$.

Current study demonstrated that there was no statistically significant relation between items of social quality of life domains except social contact leisure activities before and after the discharge plan. There was also no statistically significant relationship between studied sample and all items of psychological quality of life domain except for depression \& emotional problems before and after implementation of the discharge plan. Contrary to the findings of a study by Binjwala, et al., 2015 about " uterine prolapse and its impact on quality of life" in Nepal, which mentioned that, stages of uterine prolapse was correlated with quality of life such as physical health, emotional stress, and social limitation, intimacy, anxiety, worry and environmental problems.

From current research findings, there was statistically significant relationship between items quality of life domain of the studied sample before and after implementation of the discharge plan. A similar conclusion was reached by Osama EL Kady et, al., 2017 who studied "assessment of the prevalence of pelvic floor disorders in both vaginal and cesarean deliveries and their impact on quality of life" in Egypt clarified that the negative impact not only had a negative impact on their physical well-being but also their psychological and socioeconomic wellbeing. This finding is also supported by Dhital et al, (2013) who reported improved quality of life after surgery for pelvic organ prolapse in Nepalese women. Strengths of the current study includes testing a discharge plan and highlighting the need for health education and awareness campaign about uterine prolapse surgery among this vulnerable group. Meanwhile, current study also had certain limitation such as recall bias (2months recall period). 2- Self-reporting of data with the possibility of over and under-reporting 3- Restriction to small sample size of elderly so generalization of findings couldn't be gained

\section{CONCLUSION}

According to research hypotheses it can be conclude that, there was improvements in knowledge scores for elderly women undergoing prolapsed uterus surgery after implementation of discharge plan. A significant difference was also observed in many quality of life domains after implementation of the discharge plan.

\section{RECOMMENDATIONS}

1. Raising awareness of elderly women regarding uterine prolapse surgery.

2. Implement the discharge plan on larger sample size to gain more generalization of data.

3. Further studies are needed in this field to assess the effect of health education program on women's knowledge regarding risk factors and preventive measures to recurrence of uterine prolapse.

\section{REFERENCES}

1. Aki O., Ibrahim H., and Mamdouh H. (2014). Perceived Reproductive Morbidity and Treatment Seeking Behavior among ever Married Women in Siwa Oasis, Egypt. Journal of American Science, 7(6):749.

2. Beck AT, Steer RA and Brown GK (1996). "Manual for the Beck Depression Inventory-II". San Antonio, TX: Psychological Corporation

3. BinjwalaShrestha, SharadOnta, BishnuChoulagai, RajanPaudel , MaxPetzold,andAlexandra Krettek (2015). Uterine prolapse and its impact on quality of life in the Jhaukhel-Duwakot Health Demographic Surveillance Site, Bhaktapur, Nepal

4. Baessler K, Schussler B, Kathryn LB, Moore HK, Norton AP, Stanton LS, (2018). Pelvic floor re-education principles and practice, 2nd ed. London: Springer-Verlag; Chen GD. 1:121-4.

5. CAED (2018). Uterine prolapse study report center for agroecology and development Nepal. www.advocacynet.org

6. Deborah TR, Erpelding A, Pathak LR. (2014). Listening to "felt needs": investigating genital prolapse in Western Nepal. Reprod Health Matters. 2014; 12:166-75.

7. Detollenaere R., Robert A., Stekelenburg J., (2015). Treatment of Uterine Prolapse Stage Two or Higher.2015. Retrieved from http://www.biomedcentral.com.

8. Dhital et al, (2013). Improved quality of life after surgery for pelvic organ prolapse in Nepalese women. BMC Women's Health, 13:22.

9. Essa R. (2015). Women's awareness and reactions toward symptoms of genital prolapsed. Msc thesis, Faculty of Nursing, Alexandria (4);121-124.

10. Fritel X, Varnoux N, Zins M, Breart G, Ringa V. (2015). Symptomatic pelvic organ prolapse at midlife, quality of life, and risk factors. Obstet Gynecol, 113:609-16.

11. Gyhagen M, Bullarbo M, Nielsen TF, Milsoma I. (2015). Prevalence and risk factors for pelvic organ prolapse 20 years after childbirth: a national cohort study in singleton primiparae after vaginal or caesarean delivery. BJOG, 120:152-60.

12. Hod, M.R., Wagner, S., Greco, F., Heynemann, H. and Fornara, P. (2018). Prospective follow-up of female sexual function after vaginal surgery for pelvic organ pro- lapse using transobturator mesh implants. The Journal of Sexual Medicine, 3, 914-922.

13. Institute of Medicine and UNFPA (2018). Status of Reproductive Morbidities in Nepal. Report Submitted to UNFPA, Kathmandu.

14. Lamichhane and Tiwari, (2015). Assessment and management of pelvic organ prolapse. Obstet Gynecol Reprod Med.; 18:241-6.

15. Ministry of Health and Population (MoHP) [Nepal], (2018). New Era and ICF International Inc. Calverton, MD: MoHP, New Era and ICF International; 2017. Nepal demographic and health survey.

16. National institute for health and care excellence for uterine surgery, 2017.

17. Shah, N., Ginzberg N, \& Whitmore, K (2016). A case of pelvic organ prolapsed in the setting of cirrhotic ascites, V.18 (3); 178-180

18. Osama Saleh Hassan EL kady, Tarek Fathy Tamara, Haitham Abd EL Mohsen and Alaa Hafyz Mohamed. (2017). Egyptian journal of hospital Medicine, vol.68(2), p 1252-1256.

19. Srikrishna S, Robinson D, Cardozo L, et al. (2008). Experiences and expectations of women with urogenital prolapse: a quantitative and qualitative exploration. BJOG;115(11):1362-8.

20. Summan T. (2017). Effectiveness of nursing intervention package on prevention of utero-vaginal prolapse among mothers. M.Sc. thesis. Mangalore.

21. Shrestha B, Onta S, Choulagai B, Poudyal A, Pahari DP, Uprety A, et al. (2014). Women's experiences and health care- 
seeking practices in relation to uterine prolapse in a hill district of Nepal. BMC Women's Health, 14:20.

22. Thapa B., Rana G., and Gurung S. (2015). Contributing factors of utero-vaginal prolapse among women attended in Bharatpur hospital. Journal of Chitwan Medical College, 4(9):38-42.

23. Tamrakar A. (2015). Prevalence of Uterine Prolapse and its Associated Factors in kaski District of Napel. Journal of school of health and allied sciences, 2(1):38-41.

24. Tracee Cornforth, (2018). in a study "common conditions that can affect the uterus" Adv Clin Exp Med. 2019 Jun 28.

25. The United Nations Fund for Population Activities, and Sancharika Samuha (2017). Booklet on uterine prolapse. Kathmandu Sancharika Samuha.
26. The United Nations Fund for Population Activities, (2017) Government of Nepal. Kathmandu: Sancharika Samuha; 2017. Booklet on uterine prolapse.

27. World Health Organization (2018). Early marriages, adolescent and young pregnancies. Executive Board, 130th session, Provision agenda items 6.4.

28. Streicher LF. Uterine prolapse and pelvic relaxation. (2015). Available from:http://www.mygyne.info/uterineprolapse.htm.

29. WHOQUALITY OF LIFE - BREF (2017). Kathmandu: Government of Nepal, Operational guideline for uterine prolapse management and surgical services. 